\title{
Counterimmunoelectrophoresis in the serodiagnosis of Legionnaires' disease
}

\author{
MALCOLM G HOLLIDAY \\ From the Microbiology Department, St George's Hospital, Stafford, England
}

SUMMARY Counterimmunoelectrophoresis (CIE) was found to be a rapid, specific method for detecting circulating antibodies to Legionella pneumophila, using a simple ultrasonically disrupted antigen. The diagnostic specificity of the technique was $93 \%$ and the diagnostic sensitivity was 86. $3 \%$. Both IgM and IgG classes of antibody can be detected. There is some cross-reactivity between serogroup 1 and serogroup 6 but none between serogroup 1 and serogroups 3,4 , and 5 . It is suggested that CIE may provide a simple, reproducible screening test for Legionnaires' disease.

Difficulties encountered with the isolation of Legionella pneumophila from clinical specimens, and the subsequent diagnosis of Legionnaires' disease (LD), have placed the major diagnostic burden on serological methods.' Several methods of detecting circulating antibody in LD have been described, including immunofluorescence ${ }^{2}$ counterimmunoelectrophoresis $^{3}$ microagglutination $^{4}$ and microELISA. ${ }^{5}$

The most widely used test in England and Wales to date is the indirect fluorescent antibody (IFA) test, ${ }^{2}$ and an initial comparison of results obtained by IFA and CIE tests showed a high level of correlation. ${ }^{3}$

A degree of serological overlap between patients with LD and those with Mycoplasma pneumoniae pneumonia has been reported with IFA tests in the USA ${ }^{6}$ although the IFA technique in the UK appears to differentiate readily the two forms of pneumonia.' Furthermore, possible antigenic relationships between $L$ pneumophila and Chlamydia psittaci have been reported ${ }^{8}$ although more recent work with an improved IFA antigen showed no cross-reactions between $L$ pneumophila antigens and positive $Q$ fever, tularaemia and psittacosis sera, and that the use of an immunosorbant extracted from Escherichia coli strain 013:K92:H4 removed the only false positive result encountered with $M$ pneumoniae sera. ${ }^{9}$

In addition to problems of cross-reacting antibodies and antigens, methods used to prepare antigen have been shown to influence the results of both IFA and direct fluorescent antibody tests. ${ }^{10} \mathrm{As}$ it is possible that different antigens are involved in IFA

Accepted for publication 16 November 1982 and immunoprecipitin systems ${ }^{11}$ it was considered $\stackrel{\overrightarrow{0}}{\vec{*}}$ desirable to test further groups of sera to evaluate $\infty$ whether the CIE method suffered from crossreaction problems with sera from cases of infection with $M$ pneumoniae, $C$ psittaci and viruses, and whether with a further group of sera from LD patients obtained from several sources, the initial high correlation of results between the two methods would $\triangle$ be maintained.

\section{Material and methods}

Counterimmunoelectrophoresis was performed as described previously ${ }^{3}$ with the modification that every serum sample was tested in duplicate. A positive control using rabbit antiserum was run on every slide.

\section{ANTIGEN}

The antigen was prepared as described previously ${ }^{3} \frac{7}{0}$ with the modification that the heat-killed Legionella cells were first centrifuged and the deposit re- $\mathrm{N}$ suspended in $5 \mathrm{ml}$ of sterile physiological saline prior $\mathrm{N}$ to ultrasonic disintegration, and subsequently box- N titrated against rabbit antiserum to serogroup $1 L_{\sigma}^{\omega}$ pneumophila to find the most reactive antigen dilution in the CIE system. The concentrated sonicate was stored at $4^{\circ} \mathrm{C}$ with $0 \cdot 1 \%$ sodium azide as $\stackrel{\Phi}{\mathscr{\complement}}$ a stock solution, and was diluted for use, as required, with sterile physiological saline containing $0.1 \%$ sodium azide.

SERA

The 145 samples of serum were divided into six groups. 
Group 1 Sera from 22 confirmed cases of $L D$ with $L$ pneumophila serogroup 1 IFA titres $>16$.

Group 2 Sera from two confirmed cases of LD with $L$ pneumophila serogroup 1 IFA titres $\leqslant 16$.

Group 3 Sera from six confirmed cases of LD with IFA titres $>16$ to groups other than $L$ pneumophila serogroup 1.

Group 4 Sera from 20 cases of $M$ pneumoniae infection (IgM or isolation positive) with IFA $<16$ to L pneumophila serogroup 1.

Group 5 Sera from 79 hospital patients suffering from other illnesses and with IFA titres $<16$ to $L$ pneumophila serogroup 1.

Group 6 Sera from confirmed cases of other viral or rickettsial infection comprising:

Seven pooled high titre sera to mumps, influenza $\mathrm{A}$, influenza B, psittacosis, $\mathrm{Q}$ fever, RSV and $M$ pneumoniae, and nine high titre sera to influenza $\mathrm{A}$ (2), psittacosis (2), Q fever (2) and $M$ pneumoniae (3) all detected by complement fixation tests (CFT).

All had IFA titres $<16$ to $L$ pneumophila serogroup 1.

\section{ABSORPTION OF IgM AND IgG ANTIBODIES}

Ten $\mu$ l of positive serum was placed into each of three

Dreyers' tubes. Ten $\mu$ l antiIgM (Dako, Copenhagen,
Table 1 Results of CIE tests for the detection of circulating antibody in Legionnaires' disease. Sera from six patient groups.

\begin{tabular}{llll}
\hline Patient group & Total & $\begin{array}{l}\text { Number }+v e \\
\text { by CIE }\end{array}$ & $\begin{array}{l}\text { Number } \\
\text { by CIE }\end{array}$ \\
\hline 1 LD confirmed & & & \\
\hline $\begin{array}{l}\text { Serogroup 1 IFA } \\
>16\end{array}$ & 22 & 19 & 3 \\
$2 \begin{array}{l}\text { LD confirmed } \\
\text { Serogroup 1 IFA } \\
\quad 16\end{array}$ & 2 & 1 & 1 \\
$3 \begin{array}{l}\text { LD confirmed } \\
\text { Serogroup other than } \\
1 \text { IFA }>\text { 16 }\end{array}$ & 6 & 2 & 4 \\
$4 \begin{array}{l}\text { Mycoplasma pneumoniae } \\
\text { sera }\end{array}$ & & & \\
$\begin{array}{l}\text { Serogroup 1 IFA } \\
<16\end{array}$ & 20 & 0 & 20 \\
$5 \begin{array}{l}\text { Control sera } \\
\text { Serogroup 1 IFA } \\
<16\end{array}$ & 79 & 8 & 71 \\
$6 \begin{array}{l}\text { Viral sera } \\
\text { Serogroup 1 IFA } \\
<16\end{array}$ & 16 & 0 & 16 \\
\hline
\end{tabular}

Denmark) was placed in the first tube, $10 \mu$ lantilgG (Dako) in the second and $10 \mu \mathrm{l}$ saline in the third. These were mixed thoroughly and left at room temperature for two hours, after which they were centrifuged and the supernatant tested by CIE.

Table 2 Comparison of IFA and CIE results in tests with sera from patients with Legionnaires' disease due to serogroup 1 Legionella pneumophila

\begin{tabular}{|c|c|c|c|c|c|}
\hline \multirow[t]{2}{*}{ Serum no } & \multirow[t]{2}{*}{ Time after onset } & \multicolumn{2}{|c|}{ IFA titre (serogroup I) } & \multirow{2}{*}{$\begin{array}{l}\text { CIE result (titre) with serogroup I } \\
\text { antigen }\end{array}$} & \multirow[t]{2}{*}{ CIE antibody } \\
\hline & & $\lg G$ & $\lg M$ & & \\
\hline 1 & NA & 16 & NA & - & \\
\hline 2 & $2 \mathrm{yr}$ & 16 & NA & $+($ neat $)$ & \\
\hline 3 & 5 months & 32 & $\mathrm{NA}$ & - & \\
\hline 4 & $1-2 w k$ & 32 & NA & $+(2)$ & $\mathrm{IgM}$ \\
\hline 5 & $\mathrm{NA}$ & 32 & NA & + (neat) & \\
\hline $6 \div$ & 9 months & 64 & $<16$ & - & \\
\hline 7 & 2 months & 64 & NA & - & \\
\hline 8 & 4 months & 64 & $\mathrm{NA}$ & + (neat) & \\
\hline 9 & $3 w k$ & 64 & $\mathrm{NA}$ & $+(4)$ & IgM \\
\hline $10^{*} \$$ & $2 \mathrm{wk}$ & 128 & NA & $+(2)$ & $\operatorname{IgM}+\operatorname{IgG}$ \\
\hline $11 "$ & $2 w k$ & 128 & NA & + (neat) & \\
\hline 12 & 4 months & 128 & NA & $+(4)$ & $\operatorname{IgM}$ \\
\hline 13 & NA & 128 & $\mathrm{NA}$ & $+(2)$ & $\mathrm{IgM}+\mathrm{IgG}$ \\
\hline $14 * \S$ & $\mathrm{NA}$ & 128 & $\mathrm{NA}$ & + (neat) & \\
\hline 15 & $\mathrm{NA}$ & 180 & $<20$ & + (neat) & \\
\hline $16^{*}$ & 10 days & $<20$ & $\geqslant 180$ & $+(8)$ & $\operatorname{IgM}+\operatorname{IgG}$ \\
\hline $17 * \frac{1}{\leftarrow}$ & 30 days & $<16$ & 256 & $+(2)$ & $\operatorname{IgM}$ \\
\hline $18 \div$ & $2-3 w k$ & 256 & $\mathrm{NA}$ & $+(8)$ & IgM \\
\hline $19 \div \$$ & $3 \mathrm{wk}$ & 256 & $<32$ & $+(8)$ & IgM \\
\hline $20^{*}$ & 22 days & 16 & 400 & + (neat) & \\
\hline $21 \div \$$ & 6 months & 512 & NA & + (neat) & \\
\hline $22 \div$ & 10 days & $<20$ & 540 & $+(2)$ & $\operatorname{IgM}+\operatorname{IgG}$ \\
\hline $23 \div$ & 10 days & $<20$ & 540 & + (neat) & \\
\hline $24 * \S$ & 2 months & $>2048$ & $>2048$ & $+(32)$ & $\operatorname{IgM}+\operatorname{IgG}$ \\
\hline
\end{tabular}

${ }^{*}$ Fourfold rise in titre demonstrated in other sera.

$\div$ Single diagnostic high titre demonstrated at some time.

Legionella pneumophila isolated.

$\$$ IFA titre obtained with heat-killed antigen.

NA Not available. 
Table 3 Comparison of IFA and CIE results in tests with sera from patients with Legionnaires' disease due to other than serogroup 1 Legionella pneumophila

\begin{tabular}{|c|c|c|c|c|c|c|c|}
\hline \multirow[t]{2}{*}{ Serum no } & \multirow[t]{2}{*}{ Time after onset } & \multicolumn{2}{|c|}{ IFA titre } & \multirow[t]{2}{*}{ Serogroup } & \multirow{2}{*}{$\begin{array}{l}\text { CIE result with } \\
\text { serogroup } 1 \text { antigen }\end{array}$} & \multirow[t]{2}{*}{ Titre } & \multirow[t]{2}{*}{ CIE antibody } \\
\hline & & $\operatorname{Ig} G$ & $\lg M$ & & & & \\
\hline $\begin{array}{l}25 \dagger \\
26 * \ddagger \\
27 * \dagger \\
28 \dagger \\
29 \dagger \\
30 \dagger \$\end{array}$ & $\begin{array}{l}26 \text { days } \\
12 \text { months } \\
1 \text { month } \\
\text { NA } \\
\text { NA } \\
2 \text { months }\end{array}$ & $\begin{array}{r}64 \\
60 \\
60 \\
180 \\
540 \\
1024\end{array}$ & $\begin{array}{r}\text { NA } \\
60 \\
\geqslant 1620 \\
<20 \\
<20 \\
<16\end{array}$ & $\begin{array}{l}5 \\
6 \\
6 \\
3 \\
3 \\
4\end{array}$ & $\begin{array}{l}- \\
+ \\
+ \\
- \\
-\end{array}$ & $\begin{array}{l}\text { (neat) } \\
\text { (2) }\end{array}$ & $\operatorname{IgM}+\operatorname{IgG}$ \\
\hline
\end{tabular}

* Fourfold rise in titre demonstrated in other sera.

† Single diagnostic high titre demonstrated at some time.

† Legionella pneumophila isolated.

$\S$ IFA titre obtained with heat-killed antigen.

NA Not available.

Only sera with CIE titres $\geqslant 2$ could be tested by this method.

\section{INTERPRETATION OF IgM AND IgG ABSORPTION} TESTS

A precipitin line with only the saline diluted serum indicated that both IgG and IgM antibodies to $L$ pneumophila were involved in the CIE reaction. A line with both the saline dilution and the IgG absorbed dilution but not the IgM absorbed dilution indicated that the dominant precipitating antibody was IgM, and a line with both saline dilution and the IgM absorbed dilution, but not the IgG absorbed dilution indicated that the dominant precipitating antibody was IgG.

\section{Results}

The CIE results of the six patient groups of sera are summarised in Table 1. Of the LD sera with IFA $>16$ for serogroup 1, 19 of 22 were CIE-positive and of the LD sera from serogroup 1 cases with titres of $\leqslant 16$, one out of two was CIE-positive. The LD sera with IFA $\geqslant 16$ to serogroups other than serogroup 1 were positive in two out of six cases.

All of the $20 \mathrm{M}$ pneumoniae sera and the 16 viral and rickettsial sera were CIE-negative, and 71 of the 79 sera from patients with other illnesses were CIEnegative.

Table 2 shows the relationship between IFA and CIE results and titres with the sera from confirmed serogroup $1 \mathrm{LD}$ patients. Of the 24 sera, 20 gave a positive CIE result and of these, nine were only positive with undiluted serum. Five gave a CIE titre of 2 , two gave a titre of 4 , three gave a titre of 8 and one gave a titre of 32 .

The time elapsed between onset of disease and the withdrawal of sera, where available, varied from 10 days to two yr. CIE titres and mean elapsed times for each are as follows: CIE-negative, 5.3 months; positive neat, 5.9 months; positive $1 / 2,2.25 \mathrm{wk} ; \stackrel{\vec{\rho}}{\circ}$ positive $1 / 4,9 \cdot 5 \mathrm{wk}$; positive $1 / 8,2 \cdot 3 \mathrm{wk}$; and positive $1 / 32$, two months.

Of the 12 sera examined for the type of CIE $\vec{\nabla}$ antibody, six were IgM only and six were IgM and IgG. There was no pure IgG response. There was little obvious correlation between CIE and IFA titres.

The IFA and CIE results of the sera from cases of LD due to other than serogroup 1 are shown in Table 3 . Of the six sera, only two gave a positive CIE result. These were both serogroup 6 infections. The four CIE negative sera represented serogroups 3,4 , and 5 .

\section{Discussion}

CIE has been adapted to the detection of circulating antibody to $L$ pneumophila in $\mathrm{LD}$, and initialo investigations indicated that CIE results correlated well with those recorded using the IFA test. ${ }^{3}$

It has been shown that, if the Division of $\frac{0}{3}$ Microbiological Reagents and Quality Control (DMRQC) recommended IFA technique is followed, good agreement between results from different laboratories was obtained, but it was felt that the use of sera from four different laboratories, $\frac{D}{0}$ one of which does not use the DMRQC antigen, but a heat-killed antigen, would give a truer picture of the $N$ correlation between CIE and IFA in general use. The $N$ criteria for IFA titres considered diagnostic for LD $\mathrm{N}$ are a fourfold rise in paired sera to a titre of at least $64 \mathrm{\omega}$ or a single titre of $\geqslant 256$ with a relevant clinical history. ${ }^{13}$

In the first study there was $100 \%$ correlation between CIE and IFA with sera from confirmed LD patients, ${ }^{3}$ while in this study only $19 / 22$ sera with IFA titres $>16$ were CIE positive ( $86 \%$ correlation).

At first glance this may look as though using CIE as $\stackrel{\circ}{\mathbb{D}}$ a screening test would miss $14 \%$ of cases that are $\varrho$ positive by IFA but this is not so. In fact, on their own, none of the first nine sera tested (Table 2) with 8 
IFA titres of 16,32 and 64 would have been considered diagnostic by the DMRQC criteria, although they would have been considered suggestive with a relevant clinical history, nor would sera Nos 10 and 14 , both with titres of 128 with the heat-killed antigen, have been considered diagnostic had only a single specimen been tested. However, seven of these 11 sera gave positive CIE results. All 13 sera which would have given a diagnostic high titre by IFA were also CIE-positive.

It has been recognised that only a single serum specimen may be available for testing for $L D, 2$ therefore it is important that a screening test can provide a clear-cut indication of disease from a single sample, and it would appear that a positive CIE test would do this in $20 / 24$ of the sera tested $(83.3 \%)$ whereas IFA would provide a diagnostic titre in $13 / 24$ $(54 \%)$ and a suggestive titre in $11 / 24(46 \%)$ together with a relevant clinical history. ${ }^{12}$

It can be seen from Table 2 that the relation between IFA and CIE titres is not as close as was suggested in earlier work. ${ }^{3}$ Discrepancies between the two methods were observed regardless of the IFA antigen used to examine them. The higher CIE titres were obtained with lower mean elapsed times since onset than negative and positive neat results, however it is suggested that actual CIE titres have little value in the interpretation of whether the antibody detected is from an acute case or is residual antibody from an old case.

In patient group 3 (confirmed LD cases due to serogroups other than serogroup 1) the two sera giving CIE positive results were both serotype $6 \mathrm{~L}$ pneumophila infections (Table 3 ) whereas the four sera giving CIE negative results had IFA titres of 180 and 540 respectively to serogroup 3,1024 to serogroup 4 and 64 to serogroup 5 . These results indicate that there is some cross-reactivity demonstrable between serogroups 1 and 6 but apparently none between serogroup 1 and serogroups 3,4 , and 5 .

No serum from a patient in group 4 gave a positive CIE result (Table 1) indicating that problems of serological overlap with $M$ pneumoniae sera do not occur with LD CIE and that the two forms of pneumonia should be readily differentiated.

There were no CIE positive results with sera from patient group 6 indicating that cross-reactions with other viral or rickettsial sera should not cause falsepositive reactions in LD CIE systems.

In patient group 5, eight of the 79 sera gave CIEpositive results, a false-positive rate of $10 \%$. However, if CIE were to be used as a screening test this might prove to be acceptable because a screening test should, if possible, be oversensitive to minimise the possibility of cases being missed.

When the non-LD sera from groups 4 and 6 are considered together, no false-positives were detected whereas, in direct contrast, patient group 3 where LD was confirmed but due to other serogroups than serogroup 1, two out of six were CIE positive with serogroup 1 antigen, and in patient group 2, where LD was confirmed but IFA titres were $\leqslant 16$, one out of two were CIE-positive, showing that CIE may be positive in confirmed LD cases before IFA titres show any rise. CIE shows a diagnostic sensitivity (\% of individuals with $\mathrm{LD}$ who give a positive result) of $86 \%$ for patient group 1. The diagnostic specificity of CIE ( $\%$ of individuals without LD who give a negative result) is $90 \%$ for patient group 5 and $93 \%$ for patient groups 4,5 , and 6 considered together.

Only nine of the serogroup $1 \mathrm{LD}$ sera had both $\mathrm{IgG}$ and IgM IFA titres available. Five of these had IFA IgM titres $>16$ and IgG titres $<20$, all of which were CIE positive, and three had IgG IFA titres $>20$ and IgM titres $<16$, of which two were CIE positive and one was CIE negative. The single specimen with IgG and IgM IFA titres $>2048$ was also CIE positive. These findings would seem to indicate that CIE can detect antibodies of both the IgG and IgM classes and, if so, would be useful as it has been shown that the majority of LD patients produce IgM and only a few produce both IgM and IgG together during the first 14 days and it has been suggested that any diagnostic serological method should be capable of detecting both $\operatorname{IgM}$ and $\operatorname{IgG} .{ }^{1+}$

However, as it has been shown that precipitating antibodies to Candida are $\operatorname{IgG}$ only, ${ }^{15}$ further investigations into the class of LD CIE antibody were thought to be necessary.

Of the 12 sera tested for the class of LD CIE antibody, six were IgM and six were $\operatorname{IgM}$ and $\operatorname{IgG}$. None showed the presence of $\operatorname{IgG}$ alone but the small number of sera tested renders doubt as to whether this is a universal phenomenon and it appears that $\operatorname{IgM}$ is the dominant precipitating antibody in LD CIE systems although both IgM and IgG play a part.

For those laboratories to whom CIE is a more acceptable technique for investigation of sera for antibodies to L pneumophila than IFA it is advised that any sera found in screening to be CIE-positive, and with a relevant clinical history, be titrated by the IFA technique or sent to a reference laboratory before diagnosis is confirmed. CIE has some advantages over IFA methods particularly in the speed and economy afforded in handling large numbers of sera for routine screening and also, possibly, in ease of reading and reproducibility of results.

In view of the increasing interest and awareness regarding Legionnaires" disease, the likelihood is that more laboratories will be asked to provide a screening service, and with a diagnostic sensitivity of $86.3 \%$ and a diagnostic specificity of $93 \%$, CIE may provide a 
simple, easily performed technique for this, especially where only a single serum specimen is available.

The antigen is stable at $4^{\circ} \mathrm{C}$ for at least a year and permanent stained records can be made from the slides. Staining is recommended for all slides to minimise the possibility of missing very fine precipitin lines.

I am particularly grateful to Dr AD Macrae, PHL Nottingham; Dr RJ Fallon, Ruchill Hospital, Glasgow; Dr J Nagington, PHL Cambridge and Dr JO'H Tobin, John Radcliffe Hospital, Oxford, for their generous help and advice, and for kindly supplying the LD sera, IFA titres and relevant information; Dr AG Taylor, DMRQC, London who supplied the heat-killed Legionella cells, Mrs M Sillis, Mycoplasma Reference Laboratory, Norwich who supplied the mycoplasma sera and titres, the Regional Virus Laboratory, Birmingham and Stoke PHL who provided viral and rickettsial sera.

My thanks also to $\mathrm{Dr} E$ Nnochiri, Mr IL McCartney and the staff of the Microbiology Department, Stafford for their constant help, advice and encouragement; Dudley Guest Hospital for loan of equipment and to Mrs L Holliday and Mrs D Johnson for typing the manuscript.

\section{References}

' Johnson W, Elliot JA, Helms CM, Renner ED. A high molecular weight antigen in Legionnaires disease bacterium: isolation and partial characterisation. Ann Intern Med 1979;90:638-41.

- Taylor AG, Harrison TG, Dighero MW, Bradstreet CMP. False positive reactions in the indirect fluorescent antibody test for Legionnaires' disease eliminated by use of formolised yolk-sac antigen. Ann Intern Med 1979;90:686-9.

"Holliday MG. The diagnosis of Legionnaires' disease by counterimmunoelectrophoresis. J Clin Pathol 1980;33:1174-8.
+ Farshy CE. Cruce DD, Klein GC, Wilkinson HW, Freely JC. Immunoglobulin specificity of the microagglutination test for the Legionnaires' disease bacterium. Ann Intern Med 1979; 90:690-1.

'Farshy CE. In: Legionnaires', the disease, the bacterium and methodology. Centre for Disease Control Laboratory Manual. 1978:169.

- Grady GG. Gillfillan RF. Relation of Mycoplasma pneumoniae seroreactivity, immunosuppression and chronic disease to Legionnaires' disease. A twelve-month prospective study of sporadic cases in Massachusetts. Ann Intern Med 1979;90:60710.

'Taylor AG, Harrison TG, Andrews BE, Sillis M. Serological differentiation of Legionnaires disease and Mycoplasma pneumoniae pneumonia. Lancet 1980;i:764.

${ }^{*}$ Ormsbee RA. Peacock MG, Lattimer GL, Page LA. Fiset P. Legionnaires disease: antigenic peculiarities, strain differences and antibiotic sensitivities of the agent. J Infect Dis 1978; 138:260-4.

"Wilkinson HW, Cruce DD, Broome CV. Validation of Legionella pneumophila indirect immunofluorescence assay with epidemic sera. J Clin Microbiol 1981:13:139-46.

'" Lattimer GL, Cepil BA. Legionnaires" disease serology: effect of antigen preparation on specificity and sensitivity of the indirect fluorescent antibody test. J Clin Pathol 1980;33:585-90.

" McKinney RM. Thacker L. Harris PP et al. Four serogroups of Legionnaires disease bacteria defined by direct immunofluorescence. Ann Intern Med 1979;90:621-4.

12 Harrison TG, Taylor AG. Diagnosis of Legionella pneumophila infections by means of formolised yolk-sac antigens. J Clin Pathol 1982;35:211-4.

${ }^{13}$ Fallon RJ. Laboratory diagnosis of Legionnaires' disease. ACP Broadsheet 99.1981

it Nagington J, Wreghitt TG, Tobin JO'H, Macrae AD. The antibody response in Legionnaires disease. $J H_{y g}$ 1979:83:37781

is Lehner T, Buckley HR. Murray IG. The relationship between fluorescent. agglutinating and precipitating antibodies to Candida albicans and their immunoglobin classes. J Clin Pathol 1972;25:341-8.

Requests for reprints to: Dr MG Holliday. The Microbiology Department. St. George's Hospital, Stafford ST16 3AG, England. 